\title{
Prognosis of supravalve aortic stenosis in 81 patients in Liverpool (1960-1993)
}

\author{
D Kitchiner, M Jackson, K Walsh, I Peart, R Arnold
}

\begin{abstract}
Objective-To determine the prognosis of supravalve aortic stenosis into early adult life and the factors affecting this prognosis.

Design-81 patients with supravalve aortic stenosis were followed for a median duration of $8 \cdot 3$ (range 1 to 29) years.

Patients-40 patients $(49.4 \%)$ had Williams' syndrome, $18(22 \cdot 2 \%)$ familial supravalve aortic stenosis, $18(22 \cdot 2 \%)$ sporadic supravalve aortic stenosis, and five $(6 \cdot 2 \%)$ other syndromes. Nineteen patients had additional levels of left ventricular outflow tract obstruction.

Results -47 patients (58\%) underwent operation; $20 \%$ within a year of presentation. Multivariable analysis predicted that $88 \%$ of patients would undergo intervention within 30 years of follow up. The chance of intervention was increased by more severe aortic stenosis at presentation and the presence of multilevel obstruction in patients with sporadic supravalve aortic stenosis. Three deaths occurred before operation and 13 within a month of operation. Ten $(62 \cdot 5 \%)$ of the postoperative deaths were in patients with multilevel obstruction. Predicted survival 30 years after presentation was $66 \%$. Risk factors for survival were age and severity of aortic stenosis at presentation. Multilevel obstruction did not emerge as a significant risk factor for death because of the high association with the severity of stenosis at presentation. $74 \%$ of survivors had mild or insignificant stenosis at follow up.
\end{abstract}

Conclusions-Long-term survival is related to age and the severity of aortic stenosis at presentation. Most patients will require intervention, and most survivors will have mild stenosis.

Cardiac Unit, Royal Liverpool Children's NHS Trust

D Kitchiner

$\mathrm{K}$ Walsh

I Peart

$R$ Arnold

Institute of Child

Health, Royal

Liverpool Children's

NHS Trust, Liverpoo $M$ Jackson

Correspondence to:

Dr D Kitchiner, Cardiac

Unit, Royal Liverpool NHS

Trust, Eaton Road,

Liverpool L12 2AP.

Accepted for publication

10 October 1995

Keywords: aortic stenosis; William's syndrome; familial supravalve aortic stenosis; prognosis

Supravalve aortic stenosis is the least common type of left ventricular outflow obstruction. ${ }^{1}$ Most patients with this condition have Williams' syndrome or a positive family history, ${ }^{23}$ but about $25 \%$ of cases are sporadic. ${ }^{4}$ Progression with time has been demonstrated, ${ }^{256}$ but these reports contain relatively small numbers of patients. The aims of this study were to determine the prognosis of patients with supravalve aortic stenosis from presentation into early adult life and define the factors influencing that prognosis.

\section{Patients and methods}

Eighty one patients (52 (64\%) were male) with supravalve aortic stenosis who presented to the Royal Liverpool Children's Hospital between 1 January 1960 and 31 December 1992 were included. The severity of stenosis at presentation was determined from clinical data, together with echo/Doppler or cardiac catheterisation assessment if performed within a year of presentation. The criteria for assessing the severity of stenosis were the same as those used in a previous study. ${ }^{7}$ Patients with mild aortic stenosis had a short ejection systolic murmur and a normal electrocardiogram. A Doppler velocity of less than $3 \mathrm{~m} / \mathrm{s}$ or a peak systolic gradient of less than $40 \mathrm{~mm} \mathrm{Hg}$ across the left ventricular outflow tract at cardiac catheterisation was also used as evidence of mild stenosis. Patients with moderate stenosis had a long ejection systolic murmur and the electrocardiogram was normal or showed features of left ventricular hypertrophy. A Doppler velocity of $3-4.5 \mathrm{~m} / \mathrm{s}$ or a peak systolic gradient of $40-80 \mathrm{~mm} \mathrm{Hg}$ across the left ventricular outflow tract was also used as evidence of moderate stenosis. Patients with severe stenosis at presentation all had symptoms or left ventricular strain pattern on the electrocardiogram. The level of obstruction was determined from clinical, echocardiographic, angiographic, operative, and postmortem information. Differentiation between localised and diffuse supravalve aortic stenosis was determined by aortic or left ventricular angiography in 52 patients, echocardiography in 24 , and from operation notes in five in whom angiograms were not available. Survivors were traced to assess their current clinical status. Evaluation included clinical examination, electrocardiogram, and crosssectional and Doppler echocardiography.

\section{STATISTICAL ANALYSIS}

Frequency data are presented as raw counts or percentages, and differences between groups were assessed using the $\chi^{28}$ or Fisher's exact test $^{9}$ as appropriate. Continuously distributed data are given as medians with range, and group differences explored using the Wilcoxon's rank sum test. ${ }^{8}$ Seventy per cent confidence limits were used throughout. Time related analysis of death and first intervention 
Table 1 Age at presentation and incidence of associated conditions, and distribution of patients with supravalve aortic stenosis (SVAS) alone and those with multilevel obstruction

\begin{tabular}{|c|c|c|}
\hline & $\begin{array}{l}\text { No of } \\
\text { patients }\end{array}$ & $\begin{array}{l}\text { Median } \\
\text { (range) age } \\
\text { (months) }\end{array}$ \\
\hline Williams' syndrome & $40(49 \cdot 4)$ & $16 \cdot 7(1 \cdot 6-99 \cdot 6)$ \\
\hline Familial SVAS & $18(22 \cdot 2)$ & $6 \cdot 9(0 \cdot 2-52 \cdot 3)$ \\
\hline Sporadic SVAS & $18(22 \cdot 2)$ & $28 \cdot 6(0 \cdot 1-143 \cdot 6)$ \\
\hline Other syndromes & $5(6 \cdot 2)$ & $3.9(0 \cdot 1-15 \cdot 4)$ \\
\hline SAVAS alone & $62(76 \cdot 5)$ & $14 \cdot 6(0 \cdot 2-118 \cdot 5)$ \\
\hline Multilevel obstruction & $19(23 \cdot 5)$ & $3.9(0 \cdot 1-143 \cdot 6)$ \\
\hline
\end{tabular}

Values in parentheses are percentages. ${ }^{\star}$ Noonans $(n=2)$ Shones $(n=2)$; rubella $(n=1)$.

Table 2 Severity of aortic stenosis at presentation related to associated conditions, and the presence of supravalve aortic stenosis alone (SVAS) or multilevel obstruction

\begin{tabular}{lrll}
\hline & $\begin{array}{l}\text { Insignificant/ } \\
\text { mild stenosis }\end{array}$ & $\begin{array}{l}\text { Moderate } \\
\text { stenosis }\end{array}$ & $\begin{array}{l}\text { Severe } \\
\text { stenosis }\end{array}$ \\
\hline Williams' syndrome & 24 & 12 & 4 \\
Familial SVAS & 9 & 5 & 4 \\
Sporadic SVAS & 7 & 8 & 3 \\
$\begin{array}{l}\text { Other syndromes } \\
\text { SVAS alone }\end{array}$ & 1 & 3 & 1 \\
$\begin{array}{l}\text { Multilevel } \\
\text { obstruction }\end{array}$ & 37 & 20 & 5 \\
\hline
\end{tabular}

(surgery or balloon dilatation) after presentation (time zero) were performed actuarially ${ }^{10}$ and parametrically. ${ }^{11}$ Multivariable analyses of demographic, clinical, institutional, and morphological variables (appendix) were made in the hazard function domain ${ }^{11}$ and retained in the multivariable equation when the $P$ value for the variable was $<0 \cdot 1$.

\section{Results}

The median age at presentation was 13.8 months with a range of 3 days to 12 years.

Table 3 Distribution of other cardiac lesions in patients with supravalve aortic stenosis (SVAS) related to associated conditions

\begin{tabular}{lllll}
\hline & $\begin{array}{l}\text { Williams' } \\
\text { syndrome }\end{array}$ & $\begin{array}{l}\text { Familial } \\
\text { SVAS }\end{array}$ & $\begin{array}{l}\text { Sporadic } \\
\text { SVAS }\end{array}$ & $\begin{array}{l}\text { Other } \\
\text { syndromes }\end{array}$ \\
\hline $\begin{array}{l}\text { PPS } \\
(29 \cdot 6)\end{array}$ & 16 & 3 & 5 & 3 \\
$\begin{array}{l}\text { PVS } \\
(6 \cdot 2)\end{array}$ & 2 & & & \\
$\begin{array}{l}\text { VSD } \\
(4 \cdot 9)\end{array}$ & $1 \neq$ & 2 & 1 & $2 \dagger$ \\
$\begin{array}{l}\text { Ao arch obst } \\
\text { VSD } \pm \text { PDA } \\
(6 \cdot 2)\end{array}$ & 1 & 1 & 3 & $5(100)$ \\
Total & $20(50)$ & $6(33)$ & $9(50)$ & 5 \\
\hline
\end{tabular}

Values in parentheses are percentages. ${ }^{\star}$ One patient had aortic arch interruption. †Additional mitral valve disease. ‡Additional right ventricular outflow tract obstruction.

Ao, aortic; obst, obstruction; PDA, patent arterial duct; PPS, peripheral pulmonary artery stenosis; PVS, pulmonary valve stenosis; VSD, ventricular septal defect.

Table 4 Incidence of surgery and reoperation related to associated conditions in the 47 patients who underwent operation, and relation of surgery to the presence of supravalve aortic stenosis (SVAS) alone or multilevel obstruction

\begin{tabular}{lllll}
\hline & $\begin{array}{l}\text { No operation } \\
(n=34)(42 \cdot 0)\end{array}$ & $\begin{array}{l}\text { 1 operation } \\
(n=39)(48 \cdot 2)\end{array}$ & $\begin{array}{l}\text { 2operations } \\
(n=7)(8 \cdot 6)\end{array}$ & $\begin{array}{l}3 \text { operations } \\
(n=1)(1 \cdot 2)\end{array}$ \\
\hline $\begin{array}{l}\text { Williams' syndrome } \\
\text { Familial SVAS }\end{array}$ & 21 & 19 & & \\
$\begin{array}{l}\text { Sporadic SVAS } \\
\text { Other syndromes }\end{array}$ & 6 & 9 & 2 & 1 \\
SVAS alone & & 8 & 3 & \\
Multilevel obstruction & 34 & 3 & 2 & 1 \\
\hline
\end{tabular}

Values in parentheses are percentages.
Table 1 shows the incidence of conditions associated with supravalve aortic stenosis together with age at presentation. The age at presentation was lower in patients with familial supravalve aortic stenosis than in those with Williams' syndrome $(P<0.02)$ or sporadic supravalve aortic stenosis $(P<0.05)$. Nineteen patients had additional levels of left ventricular outflow obstruction (multilevel obstruction). Eight had aortic valve stenosis, and 11 had valve and subvalve obstruction. Diffuse supravalve aortic stenosis occurred in five patients $(26.3 \%)$ with multilevel obstruction, and in only four patients $(6.5 \%)$ with supravalve aortic stenosis alone $(P<0.05)$. There was no significant difference in the age at presentation in patients with supravalve aortic stenosis alone and those with multilevel obstruction (table 1). The incidence of multilevel obstruction was lower $(P<0.001)$ in patients with Williams' syndrome (two patients, $5.0 \%$ ) and those with familial supravalve aortic stenosis (three patients, $16.7 \%$ ) than in patients with sporadic supravalve aortic stenosis (nine patients, $50 \%$ ) and those with other syndromes (five patients, $100 \%)$.

There was no difference in the distribution of severity of aortic stenosis at presentation related to the various associated conditions ( $P$ $=0 \cdot 12$ ). However, patients with more severe stenosis at presentation had an increased tendency $(P<0.001)$ to have multilevel obstruction (table 2). Other cardiovascular lesions were found in 40 patients $(49 \cdot 4 \%)$ (table 3 ). There was no difference in the incidence of other cardiac lesions in patients with supravalve aortic stenosis alone ( $\mathrm{n}=29$; $46 \cdot 8 \%)$ and those with multilevel obstruction $(\mathrm{n}=11 ; 58 \%)$. With one exception, aortic arch obstruction occurred only in patients with multilevel obstruction. Aortic regurgitation was found at presentation in three patients $(3 \cdot 7 \%)$ who all had additional aortic valve stenosis.

The median duration of follow up in survivors was 8.3 (range 1-29) years. Nine patients were lost to follow up after a median duration of 11 (range 4.1-18.4) years. Aortic regurgitation was found in four patients with additional aortic valve stenosis at follow up. Infective endocarditis was not encountered.

INTERVENTION

Forty seven patients (58\%) underwent operation for supravalve aortic stenosis (table 4). The median age at first operation was 4.9 (range $0 \cdot 1-20.9$ ) years and there was no difference in relation to the various associated conditions. All patients underwent cardiac catheterisation before surgery and the peak systolic gradient across the left ventricular outflow tract was a median of 72 (range $42-120$ ) $\mathrm{mm} \mathrm{Hg}$. The peak systolic gradient was more than $50 \mathrm{~mm} \mathrm{Hg}$ in all but four patients who had symptoms or evidence of left ventricular strain pattern on the electrocardiogram. Three patients underwent balloon dilatation of the left ventricular outflow tract. This was successful in only one patient with isolated supravalve steno- 
Figure 1 Freedom from first intervention after presentation in 81 patients with supravalve aortic stenosis. This graph contains two depictions. The first results from an actuarial (Kaplan-Meier) analysis in which each intervention (O) is positioned actuarially along the $y$ axis and the time intervention along the $x$ axis. Bars represent $70 \%$ confidence intervals and the numbers in parentheses indicate the number of patients followed up at that interval after intervention. The second is a graphical representation of the solution to the equation (nomogram) resulting from the parametric analysis of freedom from intervention, in which a continuous point estimate ( $\longrightarrow$ ) and the $70 \%$ confidence (-- ) limits are shown. The table gives the time related depictions.

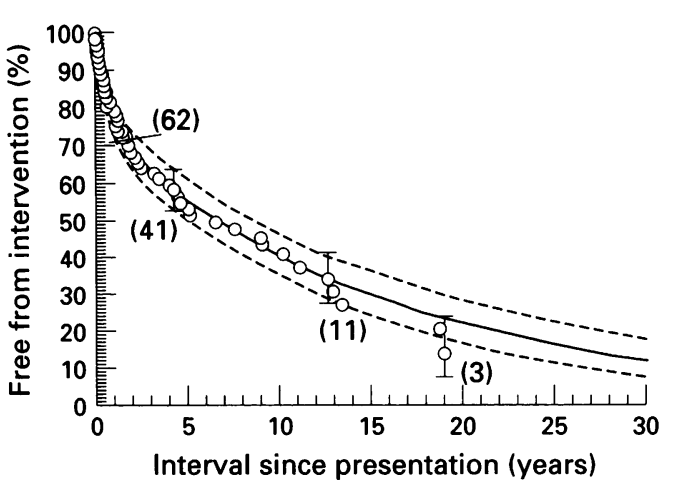

Free from intervention (\%)

$\begin{array}{lll}\begin{array}{l}\text { Interval } \\ \text { (years) }\end{array} & \begin{array}{l}\text { Life table } \\ (\%)\end{array} & \begin{array}{l}\text { Predicted } \\ \text { parametric } \\ (\%)\end{array} \\ 1 & & 81 \\ 10 & 80 & 39 \\ 15 & 43 & 29 \\ 20 & 27 & 23 \\ 25 & 13 & 16 \\ 20 & 13 & 12\end{array}$

sis who had previously had surgery. Some $20 \%$ of patients underwent intervention within a year of presentation. Actuarial and hazard analysis predicted that $88 \%$ of patients were likely to require relief of obstruction within 30 years of presentation (fig 1).

Multivariable analysis of potential risk factors (appendix) indicated that more severe aortic stenosis at presentation was the strongest determinant of the need for surgical

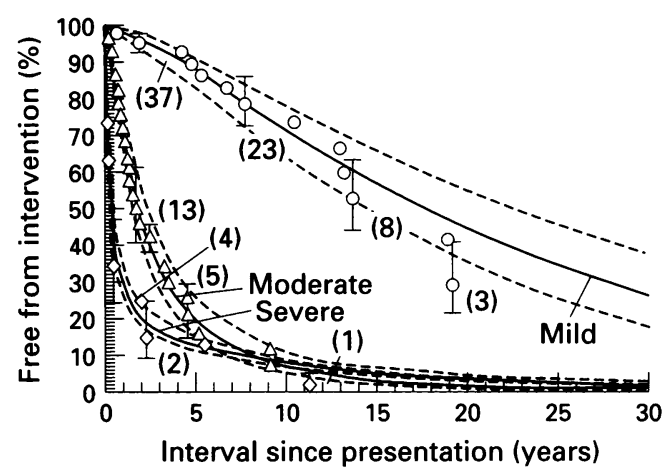

No of interventions

$\begin{array}{llll}\begin{array}{l}\text { Aortic stenosis } \\ \text { grade }\end{array} & \text { Actual } & \text { Predicted } & \text { P value } \\ \text { Mild } & & & \\ \text { Moderate } & 13 & 14.2 & 0.69 \\ \text { Severe } & 25 & 21.8 & 0.14 \\ & 9 & 10.9 & 0.05\end{array}$

Figure 2 Freedom from intervention after presentation in 81 patients with supravalve aortic stenosis stratified by severity of aortic stenosis at presentation. Kaplan-Meier estimates of freedom from intervention are depicted as in fig 1 for patients with mild $(O)$, moderate $(\triangle)$ and severe aortic stenosis $(\diamond)$ at presentation. The predicted time related freedom from intervention for each group ( $\longrightarrow$ ), obtained by averaging the predicted patient-specific freedom from first intervention estimates derived from the solution to the multivariable equation for each member of the group, and $70 \%$ confidence intervals (- - ) are shown. The table gives results from an internal validation of the multivariable equation in terms of the association between actual and predicted number of interventions for each stratum. intervention. Figure 2 shows that most patients who presented with moderate or severe stenosis underwent operation within the first few years after presentation, while patients who presented with mild obstruction gradually progressed to require intervention over a number of years. Multivariable analysis also indicated that the presence of multilevel obstruction in patients with sporadic supravalve aortic stenosis was a significant $(P=0.002)$ risk factor for intervention. The presence of Noonan's syndrome also proved significant $(P<0.05)$ in an effort to explain the intervention experiences of the two patients with this condition as both had additional severe right ventricular outflow obstruction which contributed to their early management. Factors not significant in relation to intervention were the sex of the patient, syndromes other than Noonan's syndrome, and the presence of aortic regurgitation at presentation.

The reoperation rate was $17 \%$. The incidence was higher $(P<0.01)$ in patients with multilevel obstruction than in those with supravalve aortic stenosis alone (table 4 ). The median duration between first and second operations was 4.6 (range $0 \cdot 5-8 \cdot 2$ ) years, and this was similar in patients with the various associated conditions. Table 5 shows the results of surgery.

\section{SURVIVAL}

There were 16 deaths (19.8\%) during the study period. Fourteen patients had severe aortic stenosis and two with Noonan's syndrome had additional severe pulmonary valve and peripheral pulmonary artery stenosis. The mortality was lower $(P<0.001)$ in patients with isolated supravalve aortic stenosis than in those with multilevel stenosis (table 5). Four patients with Williams' syndrome $(10 \%)$, five with familial supravalve aortic stenosis $(27 \cdot 7 \%$, three with sporadic supravalve aortic stenosis $(16.7 \%)$, and four with other syndromes $(80 \%)$ died. There were no sudden, unexpected deaths. Two patients with severe isolated supravalve aortic stenosis died before operation could be performed and one with Williams' syndrome and severe kyphoscoliosis declined surgery. Thirteen patients died within a month of operation. Three of these patients had severe isolated supravalve stenosis with profound left ventricular hypertrophy. Ten patients with multilevel obstruction died after operation. Six of these had supravalve, valve, and subvalve obstruction, one had

Table 5 Current clinical status after surgery in patients with supravalve aortic stenosis (SVAS) alone and in those with multilevel obstruction, and median age at initial operation

\begin{tabular}{lcc}
\hline & $\begin{array}{l}\text { SVAS } \\
\text { alone }\end{array}$ & $\begin{array}{l}\text { Multilevel } \\
\text { obstruction }\end{array}$ \\
\hline No stenosis & 4 & \\
Mild stenosis & 13 & 4 \\
Moderate stenosis & 6 & 2 \\
$\begin{array}{l}\text { Hospital mortality } \\
\text { (death } \leqslant 30 \text { days) }\end{array}$ & 3 & 10 \\
Lost to follow up & 2 & 3 \\
Median (range) age at & $60 \cdot 5$ & $42 \cdot 7$ \\
first operation (months) & $(9 \cdot 4-250 \cdot 9)$ & $(0 \cdot 8-229 \cdot 4)$ \\
\hline
\end{tabular}


Figure 3 Survival after presentation in 81 patients with supravalve aortic stenosis. The general form of the depictions (actuarial and parametric) are as in fig 1 , with death at any time after presentation $(O)$ in terms of survival.

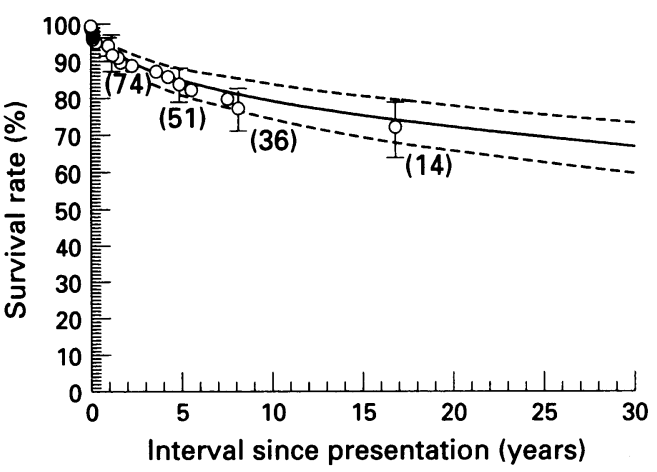

Survival rate $(\%)$

$\begin{array}{lll}\begin{array}{l}\text { Interval } \\ \text { (years) }\end{array} & \begin{array}{l}\text { Life } \\ \text { table (\%) }\end{array} & \begin{array}{l}\text { Predicted } \\ \text { parametric (\%) }\end{array} \\ 1 & 95 & 93 \\ 10 & 77 & 79 \\ 15 & 77 & 65 \\ 20 & 71 & 71 \\ 25 & 71 & 69 \\ 30 & 71 & 66\end{array}$

supravalve and valve stenosis, and three had additional surgery for right ventricular outflow tract obstruction. Four of the patients with multilevel obstruction died at reoperation and three of these operations included attempted aortic valve or root replacement. The operative mortality was lower $(P<0.005)$ in patients with supravalve aortic stenosis alone $(10.7 \%)$ than in those with multilevel obstruction $(53 \%)$.

An actuarial analysis of death at any time after presentation indicated that survival declined gradually over time (fig 3 ) to plateau at $71 \%, 17$ years after presentation. Evidence from the parametric model suggests that the proportion of patients alive after 30 years of follow up is unlikely to differ much from this value. Multivariable analysis determined that risk factors for death were more severe aortic stenosis at presentation, younger age at presentation, and the presence of Noonan's syndrome (appendix). Multilevel obstruction did not emerge as a significant risk factor because

Figure 4 Graph showing risk adjusted time related survival after presentation with supravalve aortic stenosis according to severity of aortic stenosis. The depiction is a nomogram of a specific solution of the multivariable equation (appendix) where $1 \cdot 15$ years ( 13.8 months) is the value entered for age at presentation and no for presence of Noonan's syndrome.

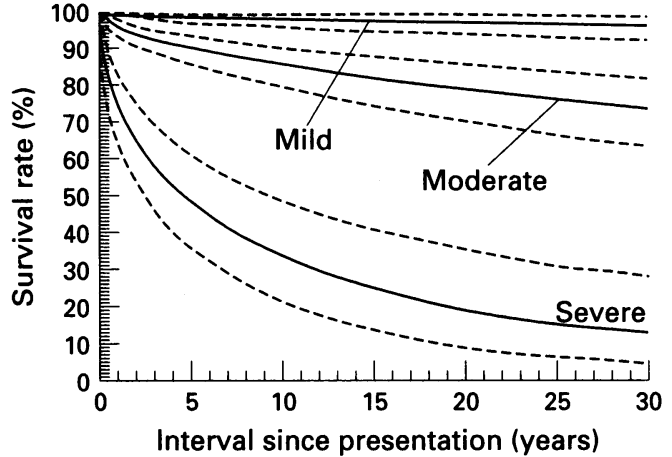

Survival (\%) according to aortic stenosis grade Interval Mild (\%) Moderate (\%) Severe (\%) (years)

$\begin{array}{llll}1 & 99.4 & 96.1 & 76.6 \\ 10 & 97.6 & 85.0 & 33.8 \\ 20 & 96.4 & 78.0 & 19.1 \\ 30 & 95.3 & 72.9 & 12.0\end{array}$

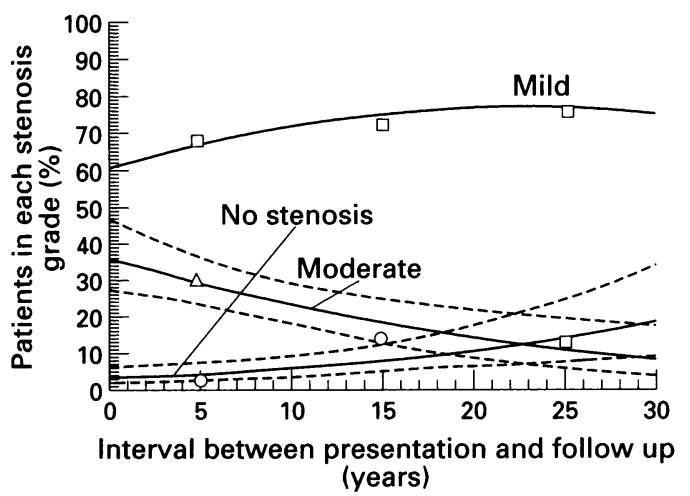

Distribution of aortic stenosis grade at follow up (\%)

$\begin{array}{llll}\begin{array}{l}\text { Interval } \\ \text { (years) }\end{array} & \begin{array}{l}\text { No } \\ \text { stenosis }\end{array} & \begin{array}{l}\text { Mild } \\ \text { stenosis }\end{array} & \begin{array}{l}\text { Moderate } \\ \text { stenosis }\end{array} \\ 1 & 3 & 62 & 35 \\ 5 & 4 & 67 & 29 \\ 10 & 6 & 71 & 23 \\ 20 & 10 & 76 & 14 \\ 30 & 18 & 74 & 8\end{array}$

Figure 5 Relation of interval between presentation and follow up with the grade of aortic stenosis severity in the 65 surviving patients at last follow up evaluation. The actual proportions of patients with no (O), mild ( $\square)$, or

moderate $(\triangle)$ stenosis (appendix) at the mid-points of 10 year intervals are represented. Nomograms of the parametric predictions of the prevalences of stenosis grade $(-)$ and $70 \%$ confidence intervals (- - ) are shown. The table gives percentage of patients in each aortic stenosis grade (total 100\%) at each time interval.

of a close association with the severity of aortic stenosis at presentation. Factors insignificant in relation to survival were the sex of the patient, the presence of syndromes other than Noonan's syndrome, and the presence of aortic regurgitation at presentation. Figure 4 shows the clear separation in time related survival in patients with mild, moderate, and severe aortic stenosis at presentation when adjusted for the presence of the risk factors of age at presentation and Noonan's syndrome. The data in fig 4 indicate that 30 year survival is predicted to be $95.3 \%$ for such a patient presenting with mild stenosis, $72.9 \%$ for one with moderate stenosis, and $12.0 \%$ for one with severe stenosis.

FOLLOW UP

Figure 5 shows the distribution of the severity of aortic stenosis in survivors at follow up. With increasing duration of follow up, there was a reduction in the proportion of patients with moderate stenosis and an increase in the number with no stenosis. The proportion of patients with mild stenosis remained fairly

Table 6 Current status of patients with supravalve aortic stenosis (SVAS) alone and those with multilevel stenosis ( $S V A S$
obstruction *

\begin{tabular}{lcc}
\hline & $\begin{array}{l}\text { SVAS } \\
\text { alone }\end{array}$ & $\begin{array}{l}\text { Multilevel } \\
\text { obstruction }\end{array}$ \\
\hline Mild stenosis & $20(32 \cdot 2)$ & \\
Moderate stenosis & $7(11 \cdot 3)$ & \\
Surgery and survived & $23(37 \cdot 1)$ & $6(31 \cdot 6)$ \\
Lost to follow up & $6(9 \cdot 7)$ & $3(15 \cdot 8)$ \\
Died & $6(9 \cdot 7)$ & $10(52 \cdot 6)$ \\
\hline
\end{tabular}

Values in parentheses are percentages. ${ }^{\star}$ Each patient appear once. 
constant at between 60 and $75 \%$. Table 6 shows the current clinical status of all patients.

\section{Discussion}

Supravalve aortic stenosis is a rare condition. Only careful follow up of patients over a long period provides an insight into its prognosis. This study comprised the largest group of patients followed from presentation. Most patients were traced and re-examined, and the duration of follow up in survivors allowed predictions of the prognosis into adult life.

\section{INTERVENTION}

Although only 47 patients (58\%) underwent intervention during the study period, hazard analysis indicated that more patients are likely to undergo intervention the longer the duration of follow up (fig 1). Patients with other levels of left ventricular outflow tract obstruction have also shown progression with time, ${ }^{1712}$ but this has not previously been confirmed in a large group of patients with supravalve aortic stenosis. The emergence of increasing severity of aortic stenosis at presentation as a risk factor for intervention, as found in this study, has also been documented in patients with other levels of left ventricular outflow tract obstruction. ${ }^{17}$ In general, the presence of multilevel obstruction was closely related to more severe aortic stenosis at presentation, but this was not the case in patients with sporadic supravalve aortic stenosis. Therefore, for the purposes of predicting the likely time intervention, the occurrence of multilevel obstruction in patients with sporadic supravalve aortic stenosis emerged as a significant risk factor, in addition to the information provided by the severity of aortic stenosis at presentation. Noonan's syndrome is a very rare association with supravalve aortic stenosis $^{13}$ and the atypical nature of the two patients with this syndrome was confirmed in the requirement for additional interventions. These two patients had additional severe pulmonary valve stenosis and intervention was also combined with relief of this obstruction.

\section{SURVIVAL}

Mortality was highest in patients with multilevel obstruction and this indicates the serious nature of this particular condition. Difficulties in the management of patients with multilevel obstruction are reflected in the high postoperative mortality in this group. Hazard analysis predicted that $66 \%$ of the study group would be alive after 30 years of follow up, and multivariable analysis indicated that the severity of aortic stenosis at presentation significantly influenced survival. Figure 4 shows the predicted risk of premature death for patients with an identical distribution of risk factors - that is, risk adjusted, in all respects other than the severity of aortic stenosis. Therefore it represents the true effect of the severity of aortic stenosis at presentation on survival. A natural order emerged in terms of premature death with increasing severity of stenosis at presentation, which has also been found in patients with other levels of left ventricular outflow tract obstruction. ${ }^{17}$

The age of the patient at presentation was also shown to modify survival significantly, with younger patients having a poorer outcome. Similar findings have been documented in patients with other levels of left ventricular outflow tract obstruction. ${ }^{1713}$ Patients with supravalve stenosis and Noonan's syndrome had a particularly poor survival record, probably because of their associated cardiac conditions. Patients with more than one level of left ventricular outflow tract obstruction are reported to have a worse prognosis than those with a single level of stenosis, ${ }^{14} 15$ but multivariable analysis has not previously been performed in relation to patients with supravalve aortic stenosis. Perhaps surprisingly, multilevel obstruction did not emerge as a significant risk factor for death. The severity of aortic stenosis at presentation was found to correlate closely with the presence of multilevel obstruction. The significantly higher mortality in patients with multilevel obstruction than in patients with supravalve aortic stenosis alone is thus accounted for by their differences in the severity of aortic stenosis at presentation.

Multilevel obstruction is more common in patients with supravalve aortic stenosis than in those aortic valve stenosis. It occurs in $20-45 \%$ of patients with supravalve aortic stenosis, ${ }^{41617}$ whereas less than $10 \%$ of patients with aortic valve stenosis have other levels of obstruction. ${ }^{1618}$ Diffuse supravalve stenosis is reported in $15-24 \%$ of patients, ${ }^{217} 18$ but was lower in the current study. These patients generally have a worse prognosis than those with localised obstruction, ${ }^{219} 20$ but again, diffuse stenosis did not emerge as a risk factor for death or intervention in this study due to a high degree of association with other identified risk factors.

\section{FOLLOW UP}

The proportion of patients with mild stenosis remained reasonable constant (fig 5). Although progression of stenosis occurred with time in patients who presented with mild stenosis, others who presented with moderate or severe stenosis underwent operation which resulted in mild residual stenosis at follow up. Other patients had complete relief of the obstruction, so the number of patients with no stenosis also increased with time. The decline in the proportion of patients with moderate stenosis with time results from intervention, as no patient improved without it.

\section{CONDITIONS ASSOCIATED WITH SUPRAVALVE AORTIC STENOSIS}

Patients with supravalve aortic stenosis commonly have associated conditions. Williams' syndrome was the most common condition associated with supravalve aortic stenosis and it occurred more frequently than previously reported. ${ }^{2021}$ No patient with Williams' syndrome required reoperation. Patients with Williams' syndrome had a relatively good prognosis with a $10 \%$ mortality, as found in another study. ${ }^{6}$ 
Familial supravalve aortic stenosis occurred almost half as frequently as Williams' syndrome, with an incidence similar to that in other series. ${ }^{22}$ In a study by Johnson et $a l^{23}$ the mean age at presentation was 14 years. With the use of cross sectional and Doppler echocardiography, ${ }^{53}$ early diagnosis is possible. Patients in the current study presented at a younger age than those with Williams' syndrome, probably because the family history encouraged early cardiac assessment.

The incidence of sporadic supravalve aortic stenosis $(22 \%)$ was a little lower than in other series, ${ }^{22}$ possibly because of careful clinical assessment for features of Williams' syndrome and a family history of supravalve aortic stenosis. The relatively older age at presentation in this group may have been because patients with Williams' syndrome or a family history were likely to undergo cardiac examination at a younger age. Reoperation was more common in patients with sporadic supravalve aortic stenosis. This reflects the significantly higher incidence of multilevel obstruction in patients with sporadic supravalve aortic stenosis than in with Williams' syndrome or familial supravalve aortic stenosis and inadequate relief of stenosis at initial operation.

Rubella syndrome is known to be associated with supravalve aortic stenosis, ${ }^{24}$ and patients with Shone's syndrome have left ventricular outflow obstruction ${ }^{25}$ which can include supravalve aortic stenosis. The association of Noonan's syndrome with supravalve aortic stenosis is extremely rare. The incidence of these syndromes was low but all had multilevel obstruction. In some ways they were not representative of patients with supravalve aortic stenosis. However, multilevel obstruction did occur in other patients with supravalve aortic stenosis, so it was considered that these patients should not be excluded. Patients with these syndromes presented at a young age, all had other cardiac lesions, and all required surgery for supravalve aortic stenosis. They had the highest mortality of any subgroup, which consisted entirely of early postoperative deaths. Noonan's syndrome emerged as a significant $(P<0.02)$ risk factor for intervention and death because of unsuccessful attempts to relieve the coexistent severe right ventricular outflow tract obstruction.

The incidence and distribution of other cardiac lesions was similar to that in other published series. ${ }^{6}{ }^{17}$ The most common lesion was peripheral pulmonary artery stenosis, which occurred in patients with Williams' syndrome and those with the familial types of supravalve aortic stenosis, but was also found in patients with sporadic supravalve aortic stenosis. The higher incidence of aortic arch obstruction in patients with multilevel obstruction emphasises the diffuse nature of left ventricular outflow tract obstruction.

Infective endocarditis occurs in patients with supravalve aortic stenosis ${ }^{18}$ but was not encountered in this study. Sudden death did not occur in any patient in this study but it has been reported, in relation to severe supravalve aortic stenosis and obstruction of coronary ostia in patients with mild stenosis. ${ }^{186}$

\section{Conclusions}

Patients with severe supravalve aortic stenosis present early and undergo intervention at a young age. Patients who present with moderate or mild stenosis fare better, but most will require intervention. Most survivors will have mild stenosis.

The authors thank Eugene $\mathrm{H}$ Blackstone for guidance in the use of the parametric analysis of time related events. MJ is supported by a grant from the Cardiac Fund, Royal Liverpool ported by a grant from

1 Kitchiner DJ, Jackson M, Malaiya N, Walsh K, Peart I, Arnold $R$. The incidence and prognosis of left ventricular outflow obstruction in Liverpool (1960-1991). Br Hear f 1994;71:588-95.

2 Flaker G, Teske D, Kilman J, Hosier D, Wooley C. Supravalvular aortic stenosis. A 20 -year clinical perspective and experience with patch aortoplasty. $A m \mathcal{F}$ Cardio $1983 ; 51: 256-60$

3 Jones KI, Smith DW. The Williams elfin facies syndrome. A new perspective. $\mathcal{F}$ Pediatr 1975;86:718-23.

4 Pansegrau DG, Kioshos AM, Durnin RE, Kroetz FW. Supravalvular aortic stenosis in adults. $\mathrm{Am} \mathcal{f}$ Cardio 1973;31:637-41.

5 Wren C, Oslizlok P, Bull C. Natural history of supravalve aortic stenosis and pulmonary artery stenosis. $\mathcal{F} \mathrm{Am} \mathrm{Coll}$ Cardiol 1990;15:1625-30.

6 Zalzstein E, Moes CAF, Musewe NN, Freedom RM. Spectrum of cardiovascular anomalies in WilliamsBeuren syndrome. Pediat Cardiol 1991;12:219-23.

7 Kitchiner DJ, Jackson M, Walsh K, Peart I, Arnold R. The incidence and proonosis of congenital aortic valve stenosis; Liverpool (1960-1990). Br Heart $f$ 1993;69:71-9.

8 Armitage P, Berry G. Statistical methods in medical research. 2nd ed. Oxford: Blackwell Scientific Publications, 1987: 2nd ed. Oxf

9 Fisher RA. Statistical methods and scientific reference. 3rd ed. New York: Hafner Press, 1973:71-8.

10 Kaplan EL, Meier P. Nonparametric estimation from incomplete observations. Am Stat Assoc $\mathcal{F}$ 1958;53: 457-81.

11 Blackstone EH, Naftel DC, Turner ME Jnr. The decomposition of time varying hazard into phases, each incorporating a separate stream of concomitant information. $f$ Am Stat Assoc 1986;81:615-24.

12 Walker SH, Duncan DB. Estimation of the probability of an event as a function of several independent variables. Biometrika 1967;54:167-79.

13 Keane JF, Dirscoll DJ, Gersony WM, Hayes CJ, Kidd L, O'Fallon WM, et al. Second natural history study of congenital heart defects. Results of treatment of patients with aortic valvar stenosis. Circulation 1993;87(suppl I):11-27.

14 Sreeram N, Kitchiner D, Smith A. Spectrum of valva abnormalities in Noonan's syndrome: a pathologic study. Cardiol Young 1994;4:62-6.

15 Fisher RD, Mason DT, Morrow AG. Results of operative treatment in congenital aortic stenosis. Pre- and postoperative hemodynamic evaluations. If Thorac Cardiovasc Surg 1970;59:218-24.

16 Kirklin JW, Barratt-Boyes BG. Congenital discrete subvalvular aortic stenosis. In: Kirklin JW, Barratt-Boyes BG, eds. Cardiac surgery. New York: John Wiley and Sons, 1986:972-1012.

17 Sharma BK, Fujiwara H, Hallman L, Ott DA, Reul GJ, Cooley DA. Supravalvar aortic stenosis: a 29-year review of surgical experience. Ann Thorac Surg 1991;51:1031-9.

18 Peterson TA, Todd DB, Edwards JE. Supravalvular aortic stenosis. $f$ Thorac Cardiovasc Surg 1965;50: aortic $734-41$.

19 Bernhard WF, Keane JF, Fellows KE, Litwin SB, Gross RE. Progress and problems in the surgical management of congenital ao

20 Rastelli GC, McGoon DC, Ongley PA, Mankin HT Kirklin JW. Surgical treatment of supravalvular aortic stenosis. Report of 16 cases and review of literature. $\mathscr{f}$ Thorac Cardiovasc Surg 1966;51:873-82.

21 Keane JF, Fellows KE, LaFarge CG, Nadas AS, Bernhard WF. The surgical management of discrete and diffuse supravalvar aortic stenosis. Circulation 1976;54:112-7.

22 Martin EC, Moseley IF. Supravalve aortic stenosis. $B$ Heart $\mathcal{F}$ 1973;35:758-65.

23 Johnson LW, Fishman RA, Schneider B, Parker FB Husson G, Webb WR. Familial supravalvular aortic stenosis. Report of a large family and review of the literature. Chest 1976;70:494-500.

24 Weyman AE, Caldwell RL, Hurwitz RA, Girod DA, Dillon JC, Feigenbaum H, et al. Cross-sectional echocardiographic characterization of aortic obstruction. 1. Supravalvular aortic stenosis and aortic hypoplasia. Circulation 1978;57:491-7. 
25 Varghese PJ, Izukawa T, Rowe RD. Supravalvular aortic tenosis as part of rubella syndrome, with discussion of pathogenesis. Br Heart $\mathcal{F}$ 1969;31:59-62.

26 Shone JD, Sellers RD, Anderson RC, Adams P, Lillehei CE, Edwards JE. The development complex of "parachute mitral valve" supravalvular ring of left atrium subaortic stenosis and coarctation of the aorta. Am $\mathcal{f}$ Cardiol 1963;11:714-25.

\section{Appendix}

VARIABLES ENTERED INTO MULTIVARIABLE ANALYSES OF FREEDOM FROM FIRST INTERVENTION AND DEATH AT ANY TIME

Demographic age at presentation (with transforms), sex. Clinical aortic stenosis severity at presentation (with transforms), presence of aortic regurgitation, presence of Noonan's, rubella, Shone's or Williams' syndrome, and familial supravalve aortic stenosis.

Institutional interval from first patient presenting to Royal Liverpool Children's Hospital to date of presentation (with transforms).

Morphology level of obstruction: diffuse or localised supravalve aortic stenosis. These factors were considered as isolated potential risk factors and as interactive terms (product of two potential risk factors).

FREEDOM FROM FIRST INTERVENTION AT ANY TIME AFTER PRESENTATION

Parameter estimates: single declining hazard phase $\mu_{3}=$ $0.04210502, \tau=1, a=1, \gamma=1, \eta=0.651$.

Shaping parameter estimates and the regression coefficients, standard deviations, and $\mathrm{p}$ values (in parentheses) of the multivariable risk factor equation: $\tau=1, a=1, \gamma=1, \eta=0.265$, intercept $=0.00055946$, aortic stenosis severity at presentation -1 , multiplied by interval from first patient presenting to Royal Liverpool Children's Hospital to date of presentation ${ }^{1}$ $0.010(0.001)(P \leqslant 0.0001)$, presence of multilevel obstruction (in patients with sporadic supravalve aortic stenosis) $1.436(0.389) \quad(P=0.002)$, presence of Noonan's syndrome $1.586(0.703)(P=0.033)$.

FREEDOM FROM DEATH AT ANY TIME AFTER PRESENTATION

Parameter estimates: single declining hazard phase $\mu_{3}=$ $0.02312534, \tau=1, a=1, \gamma=1, \eta=0.488$.

Shaping parameter estimates and the regression coefficients, standard deviations, and $p$ values (in parentheses) of the multivariable risk factor equation: $\tau=1, a=1, \gamma=1, \eta=0.610$, intercept $=0.00054268$, aortic stenosis severity at presentation $1.899(0.40)$ $(P \leqslant 0.0001$ ), age at presentation (natural logarithmic transform) $-0.386(0.12)(P=0.001)$, presence of Noonan's syndrome $2 \cdot 222(0.89)(P=0.013)$.

This variable was created for each patient in the study from the transformation of severity of aortic stenosis (by subtracting 1) and multiplying it with the interval from first patient to each patient's date of presentation, and was necessary to reflect the increasing probability of intervention with experience of the hospital in correcting supravalve aortic stenosis. 